\title{
Análise argumentativa da ironia standard e da ironia não-standard ${ }^{1}$
}

\author{
Analyse argumentative de I'ironie standard et de I'ironie non-standard
}

\author{
Saori Nishiwaki \\ École des Hautes Études en Sciences Sociales - Paris - França
}

\begin{abstract}
Resumo: Este artigo visa examinar, no quadro da Teoria dos Blocos Semânticos (TBS), a natureza do conteúdo da ironia que se baseia na contradição e da ironia que se baseia no exagero. Definiremos a ironia que se baseia na contradição como caso de "discordância absurda", e a ironia que se baseia no exagero, como caso de "discordância sobre a intensidade". Diante da hipótese dominante na linguística francesa, segundo a qual a ironia é um fenômeno enunciativo que se caracteriza pelo deslocamento, sustentaremos que a ironia é um fenômeno argumentativo que se define pelo conteúdo estranhamente deslocado.
\end{abstract}

Palavras-chave: Teoria dos Blocos Semânticos (TBS); Ironia; Conteúdo; Enunciação, Discursos políticos

Résumé: Le présent article vise à examiner, dans le cadre de la Théorie des Blocs Sémantiques (TBS), la nature du contenu de l'ironie se basant sur la contradiction et de l'ironie se basant sur l'exagération. Nous définirons l'ironie se basant sur la contradiction comme le cas de "décalage absurde", et l'ironie se basant sur l'exagération, comme le cas de "décalage concernant l'intensité". Face à l'hypothèse dominante dans le domaine de la linguistique française selon laquelle l'ironie est un phénomène énonciatif qui se caractérise par la prise de distance, nous soutiendrons que l'ironie est un phénomène argumentatif qui se définit par le contenu bizarrement décalé.

Mots-clés: Théorie des Blocs Sémantiques (TBS); Ironie; Contenu; Énonciation; Discours politiques

\section{Introdução}

O presente artigo diz respeito à ironia verbal. A ironia, no sentido que a linguística tem mais frequentemente associado ao termo se resumiria talvez em antífrase ou, em todo caso, em distanciamento: o locutor não sustentaria o que diz ${ }^{2}$. Entretanto, a observação dos dados permite perceber que os utilizadores da linguagem podem muito bem qualificar como irônicos, não somente os enunciados que são antifrásicos, mas igualmente enunciados que tomam outras formas que não a antífrase ${ }^{3}$. O que me

\footnotetext{
1 Tradução: Leci Borges Barbisan - PPG Letras - PUCRS.

2 Por exemplo, o Grand dictionnaire linguistique et sciences du langage, de Larousse (na página 258 da edição de 2007) define ironia como "figura que consiste em dizer o contrário do que se quer dizer para zombar e não para enganar". Sperber e Wilson $(1978,1989)$ falavam de "menção ecóica" e Ducrot $(1984,2010)$ falava de "polifonia".

3 Certos autores que estudaram a ironia no sentido estrito do termo admitiram que a ironia é, de fato, um fenômeno mais amplo: "O emprego em francês da palavra 'irônico' é, evidentemente mais amplo do que o que
}

interessa é a ironia no sentido amplo que os utilizadores da linguagem associam ao termo, e meu trabalho atual consiste em encontrar e descrever o parentesco entre esses diversos tipos de ironia, afim de reduzir a distância entre a teoria linguística e o estado real de utilização da linguagem.

Nessa ótica, me esforçarei, no que segue, para ampliar a análise da ironia proposta por Carel (2011a, 2011b, 2012) no quadro da Teoria dos Blocos Semânticos (TBS). Essa autora tinha, como objeto de estudo, a ironia chamada standard. Eu me proponho, de minha parte, a

eu faço aqui, e pode cobrir casos como o seguinte - ele é inspirado por um romance de P.D. James: (3) Cordélia chegou cedo em Eastbourne e, para esperar, tomou um chá na praça principal. Uma estátua da Rainha Vitória com vestimenta pomposa estava lá, em pé, com o cetro na mão, o braço levantado na direção dos banheiros públicos" (CAREL, 2011b, p. 57). “É forçoso, todavia, reconhecer que a maioria dos empregos de 'ironia' e de "ironizar" encontrados no dia-a-dia são de tipo que se referem a enunciados que se contentam com atacar um alvo em termos mais ou menos engraçados ou “espirituosos'.” (KERBRAT-ORECCHIONI, 2013, p. 54). 
tratar de um caso não standard e a mostrar que a noção de distanciamento, da TBS, permite dar uma explicação unificada à ironia standard e à ironia não-standard, levando em conta ao mesmo tempo suas afinidades e suas diferenças. No final da análise, duas questões teóricas serão levantadas.

\section{Dois exemplos}

Comecemos observando os dois exemplos seguintes (sublinhados pela autora):

(1) "É sempre encorajador vir vê-los! Vocês têm um ar de entusiasmo, de fato!", disse em tom de brincadeira Sarkozy, ao entrar no salão verde do Elysée. Descontraído e brincalhão, ele zombou das "caras" de seus colaboradores. (Le Figaro, 21 de abril de 2012)

(2) Nas pesquisas de opinião, as intenções de voto continuam favorecendo lentamente Hollande. Ele ironiza esses saltos do presidente-candidato. "Às vezes, ele [Sarkozy] readquire confiança porque, pela leitura de certas pesquisas, ele seria derrotado menos claramente do que o previsto" (Le Figaro, 7 de abril de 2012)

Trata-se de enunciados de personalidades políticas francesas, observados durante a campanha presidencial francesa de 2012. Lembro que Sarkozy e François Hollande eram ambos candidatos à eleição presidencial em 2012: Sarkozy presidente saindo e candidato da UMP (direita) foi derrotado pelo candidato do Partido Socialista (esquerda) Hollande, que é atualmente presidente da República. No exemplo (1), Sarkozy zomba de seus colaboradores que fazem umas caras por causa de um resultado desfavorável a Sarkozy das pesquisas sobre as intenções de voto, enquanto no exemplo (2) Hollande ridiculariza Sarkozy, que se aproxima ligeiramente de Hollande nas sondagens sobre a intenção de voto.

Observar-se-á que esses enunciados têm, ambos, algo ilógico, estranho e inesperado, mas de modo diferente. Admite-se contradição no conteúdo de (1) no qual o locutor parece sustentar que as caras de seus colaboradores são encorajadoras e entusiasmantes, enquanto pelo conteúdo de (2) contenta-se com observar uma certa estranheza que não chega nem mesmo à contradição. O locutor de (2) parece sustentar a retomada de confiança de Sarkozy por causa de um resultado das pesquisas que não é muito favorável, mas ele admite, mesmo assim, que o resultado das pesquisas não era ruim para Sarkozy. Vê-se aí um certo exagero, mais do que uma contradição. Resumirei essas observações dizendo que (1), no qual o locutor parece sustentar um conteúdo contraditório, é um caso de ironia que se baseia na contradição e que (2), no qual o locutor parece sustentar parcialmente um conteúdo exagerado, é um caso de ironia baseado no exagero. Eu denominarei, de outro ponto de vista, (1) ironia standard e (2) (um tipo de) ironia não standard.

Mais globalmente, como vimos no início, entendo como "ironia" uma definição muito ampla, Entendo intuitivamente como ironia" um ataque verbal, engenhoso e bem formulado, quer seja gentil ou maldoso. Suporei a seguir que existem várias formas de ironia, caracterizadas cada uma por técnicas de fala humorística próprias. Essa técnica pode ser uma contradição, um exagero ou outras coisas mais. Eu me proponho igualmente a considerar que a ironia que se baseia na contradição como ironia standard, no sentido de que se trata dos casos típicos nos quais se reconhece imediatamente a ironia - que dia lindo! dito diante de uma tempestade, por exemplo - e direi que a ironia que se baseia em algo diferente da contradição - é o caso de (2) que se apoia no exagero, por exemplo - é uma ironia não standard porque se trata dos casos mais particulares e atípicos sobre os quais pode-se discutir se é ironia ou não. Evidentemente, há outros tipos de ironia não standard além daquela que é baseada no exagero - foi por isso, aliás, que falei de um tipo de ironia não-standard - mas neste artigo deixarei de lado a análise de outros tipos de ironia não standard para me dedicar unicamente ao da ironia de tipos (1) e (2). Assinalo, enfim, que a definição de ironia que acabo de dar é intuitiva - admito isso, é claro. Precisar e formalizar essa definição é o objetivo maior de meu trabalho.

\section{A TBS}

\subsection{Aspecto argumentativo e encadeamento argumentativo}

Antes de descrever os exemplos de ironia pela linguagem da TBS (Teoria dos Blocos Semânticos), preciso esboçar o essencial da teoria ${ }^{4}$.

A TBS, que se situa na linha da Teoria da Argumentação na Língua desenvolvida por Anscombre e Ducrot (1983), afirma que todo enunciado é parafraseável por discursos argumentativos. Mais tecnicamente, afim de descrever o conteúdo do enunciado, a TBS propõe parafraseá-lo por "um encadeamento argumentativo" e associar a cada encadeamento um "aspecto argumentativo". O conteúdo do enunciado é, portanto, descrito por essas duas noções argumentativas que são o encadeamento argumentativo e o aspecto argumentativo.

\footnotetext{
4 Eu me refiro aqui principalmente a Carel (2011a, 2011b, 2012) e a Kida (no prelo a, no prelo b)
} 
Entende-se como encadeamento argumentativo uma sequência de duas frases sintáticas, ligadas por um conector do tipo de portanto (por isso, porque, consequentemente etc.) ou do tipo de no entanto (entretanto, até mesmo se, apesar de que etc.). O primeiro é chamado encadeamento normativo, o segundo, encadeamento transgressivo. Além disso, entende-se por aspecto argumentativo um esquema argumentativo como X DC Y e X PT Y. O primeiro é chamado aspecto normativo, $\mathrm{o}$ segundo, aspecto transgressivo. $\mathrm{O}$ encadeamento argumentativo é entendido como concretizando o aspecto argumentativo. $\mathrm{O}$ aspecto argumentativo expressa $\mathrm{o}$ sentido preciso do encadeamento argumentativo que ele concretiza. Eis alguns exemplos:

(3) Pedro é prudente.

(4) PERIGO DC PRECAUÇÃO

(5) Se há perigo, Pedro toma precauções

(6) Maria é inteligente.

(7) DIFÍCIL PT COMPREENDE

(8) Até mesmo se é difícil Maria compreende.

Assim, o conteúdo do enunciado (3) é descrito ao mesmo tempo pelo aspecto argumentativo normativo (4) e pelo encadeamento argumentativo normativo (5). Dá-se o mesmo com o enunciado (6), cujo conteúdo é descrito por duas noções argumentativas transgressivas, neste caso. Admite-se que o aspecto argumentativo transgressivo como (7) e o encadeamento argumentativo transgressivo como (8) constituem o conteúdo do enunciado (6).

\subsection{Distanciamento entre aspecto e encadeamento}

Além disso, a TBS constata que há vários tipos de relação entre o aspecto e o encadeamento. Nos casos como (3)-(5) e (6)-(8), onde se encontram as mesmas expressões, ao mesmo tempo, no aspecto argumentativo e no encadeamento argumentativo, a TBS diz que o encadeamento argumentativo relaciona-se com o aspecto argumentativo que ele reflete. Nesse caso, essa dupla indicação pareceria redundante. No entanto, esse não é sempre o caso. $\mathrm{O}$ encadeamento pode não estar relacionado ao aspecto que ele reflete. Nesse caso, a TBS diz que há "distanciamento".

(9) Este soldado atravessou com coragem as linhas do inimigo.

(10) PERIGOSO PT FAZ

(11) Eram as linhas do inimigo no entanto esse soldado as atravessou.
O conteúdo do enunciado (9) é descrito ao mesmo tempo pelo aspecto argumentativo (10) e pelo encadeamento argumentativo (11). Ao contrário dos exemplos (3)-(5) e (6)-(8), aqui não se encontra o mesmo termo no aspecto e no encadeamento. Certos distanciamentos são banais como os exemplos (9)-(11) - porque o termo as linhas do inimigo é associado comumente e talvez até mesmo linguisticamente ao termo perigo - mas outros distanciamentos não são banais e provêm do sentido do locutor.

(12) Pedro, com coragem, provou chicória.

(13) PERIGOSO NO ENTANTO FAZ

(14) Tratava-se de provar chicória no entanto Pedro fez

Como sempre, (12) é o enunciado cujo conteúdo deve ser descrito, e (13), o aspecto (14), o encadeamento. Aqui, o distanciamento entre o aspecto e o encadeamento não é banal. O fato de associar a expressão provar chicórias ao termo perigoso é incontestavelmente inesperado. No caso do conteúdo do enunciado irônico, há também distanciamento, mas isso será visto um pouco mais tarde.

\subsection{Função textual}

A TBS propõe não apenas ferramentas para descrever o conteúdo do enunciado, mas também o modo de apresentar esse conteúdo ${ }^{5}$. A TBS supõe que um enunciado pode comunicar vários conteúdos e que cada conteúdo exerce uma função textual que lhe impõe certa restrição no nível da organização do discurso. Há três tipos de função: "assumir", "evocar", ou enfim "excluir". Vou ilustrá-las uma após a outra.

Um conteúdo assumido não deve ser contrariado pela sequência do discurso e se articula à sequência do discurso;

\section{(15) Faz bom tempo. Vamos passear.}

Assim, o conteúdo [o tempo está bom] comunicado pelo enunciado faz bom tempo é assumido, no sentido de que esse conteúdo não é contrariado e é desenvolvido pelo enunciado que o segue, vamos passear. Um conteúdo evocado não pode ser contrariado, - do mesmo modo que um conteúdo assumido - mas ele não se articula à sequência do discurso.

\footnotetext{
5 A Teoria Argumentativa da Polifonia (ver, por exemplo, ver Carel [2011a, 2011b] ocupava-se com o modo de apresentar o conteúdo, mas ela será englobada pela TBS num futuro próximo. Além disso, há uma mudança de terminologia nas duas funções textuais: assumir - afirmar, concordar - evocar (Carel: comunicação pessoal).
} 
*(16) Maria, que estava cozinhando, ouviu o telefone tocar. Mas ela estava nervosa.

O locutor do enunciado Maria, que estava cozinhando, ouviu o telefone tocar evoca o conteúdo sintaticamente pressuposto [Maria estava cozinhando]. Isso se explica pela impossibilidade de (16). O conteúdo [Maria estava cozinhando] não se articula imediatamente no discurso.

Enfim, diz-se que um conteúdo excluído é um conteúdo que o locutor se empenha em não afirmar na continuação. O exemplo típico do conteúdo excluído é dado pelos enunciados que comportam a negação não (ne...pas) e, entre outros, seu emprego metalinguístico:

(17) Ele não é corajoso; ele é audacioso.

Assim, o segmento não é corajoso não atribui ao homem uma forma fraca de covardia; o locutor exclui o conteúdo [ele é corajoso] e assume o conteúdo da proposição seguinte [ele é audacioso]. A questão é que o locutor não se opõe ao conteúdo excluído, ele se contenta com não utilizá-lo. No caso da ironia, como veremos na continuação, a função do conteúdo comunicado pode ser distinta.

\section{Aplicação à ironia standard}

Armados agora para descrever as ironias pela linguagem da TBS, voltemos aos exemplos iniciais. Reproduzo abaixo o exemplo da ironia standard, e aplico os trabalhos de Carel (2011, 2012a, 2012b) nos quais esse tipo de ironia é estudado.

(1) "É sempre encorajador vir vê-los! Vocês têm um ar de entusiasmo de fato!", brincou Sarkozy ao entrar no salão verde do Elysée. Descontraído e brincalhão, ele zombou das "caras" de seus colaboradores. (Le Figaro, 21 de abril de 2012).

O primeiro enunciado é sempre encorajador vir vê-los seria parafraseável por (19), entendido como concretizando (18):

\section{(18) ENÉRGICO PORTANTO ENCORAJADOR}

(19) Vocês estão com umas caras, portanto é sempre encorajador vir vê-los.

Vê-se o distanciamento entre o aspecto e o encadeamento que constituem o conteúdo desse enunciado. E esse distanciamento é "absurdo", porque um dos aspectos associados à expressão caras é algo como:

\section{(20) NÃO ENÉRGICO PORTANTO NÃO ENCORA-} $\mathrm{JADOR}^{6}$

Vê-se ai a relação de contradição. Além disso, os conteúdos (18) e (19) são excluídos, de modo que não são afirmados na sequência do discurso. ${ }^{7}$

Dá-se o mesmo no segundo enunciado vocês parecem entusiasmados, de fato. O enunciado é parafraseável por (22), entendido como concretizando (21):

\section{(21) ENÉRGICO DC ENTUSIASMADO}

(22) Porque vocês fazem essas caras, vocês têm de fato um ar de entusiasmados.

Também aqui, vê-se o distanciamento absurdo entre o aspecto e o encadeamento que constituem o conteúdo do enunciado. Porque pode-se associar igualmente à expressão caras um aspecto argumentativo como:

\section{(23) NÃO ENÉRGICO DC NÃO ENTUSIASMADO}

Vê-se aí a relação de contradição, como constatamos acima com (18) e (19). Além disso, os conteúdos (20) e (21) são excluídos, do mesmo modo que (18) e (19) - os conteúdos (20) e (21) não são afirmados na sequência do discurso ${ }^{8}$. Assim, quanto à ironia standard, há uma discordância absurda entre o aspecto argumentativo e o encadeamento argumentativo, e o locutor exclui o conteúdo.

\section{Aplicação à ironia não standard}

\subsection{Análise}

Passemos agora ao exemplo da ironia não standard, que ainda não é tratada no contexto da TBS. Vou reproduzir abaixo o exemplo (2).

(2) Nas pesquisas de opinião, as intenções de voto continuam a tender lentamente para Hollande. Ele faz ironia sobre os saltos do presidente candidato "Às vezes, ele [Sarkozy] adquire confiança porque, pela leitura de certas pesquisas, ele seria derrotado menos nitidamente do que o previsto" (Le Figaro, 7 de abril de 2012).

\footnotetext{
6 NEG (ne ... pas) é um operador de negação.

7 Já que o discurso continua assim: "No fundo, o presidente mostrou-se sereno. Eu nunca vi uma campanha como essa, lançou ele. Até mesmo em 2007 havia menos pessoas nos meetings." Um colaborador, admirado: "É inacreditável Ele fica imperturbável. Ele está convencido de que ele é compreendido pelos franceses. Ele sente uma mobilização sem precedentes de nosso eleitorado. Ele acredita nisso." (Le Figaro, abril 2012)

8 Ver a nota 6.
} 
O conteúdo do enunciado é descrito por um aspecto como (24) e um encadeamento como (25).

\section{(24) NÃO DERROTA DC NÃO DECEPCIONADO}

(25) Às vezes ele readquire confiança porque, pela leitura dessas pesquisas, ele seria derrotado menos nitidamente do que o previsto.

Vê-se que há distanciamento entre o aspecto e o encadeamento. Entretanto, o distanciamento não atinge o absurdo como no caso da ironia standard, no qual há contradição entre o aspecto e o encadeamento. Aqui, a relação entre o primeiro segmento do encadeamento ele readquire confiança e o segundo segmento do aspecto NÃO DECEPCIONADO não é contraditória; o primeiro segmento do encadeamento ele readquire confiança é "forte" demais em relação ao segundo segmento do aspecto NÃO DECEPCIONADO. Desenvolvamos esse ponto. A meu ver, as significações das expressões readquirir confiança e não ficar decepcionado têm, ambas, algo positivo, mas há uma diferença importante de grau na positividade afirmada por essas duas expressões. Isso se explica pela aceitabilidade do enunciado (26) e a impossibilidade de $*\left(26^{\prime}\right)$ :

(26) Ele não está decepcionado, pode-se até mesmo dizer que ele readquire confiança.

*(26’) Ele readquire confiança, pode-se até mesmo dizer que ele não está decepcionado.

Como mostra esse teste, há gradualidade entre as duas expressões não estar decepcionado e readquirir confiança, e a positividade afirmada por readquirir confiança é mais importante do que a positividade afirmada por não estar decepcionado. Essa diferença de graus constitui, creio eu, a fonte do distanciamento específico no conteúdo do enunciado tipo (2). Como prova, essa relação de gradualidade não é observável no conteúdo da ironia standard como em (18) e (19) ou em (20) e (21). Pode-se fazer o mesmo teste, mas o resultado não é o mesmo. Assim, nem (27) nem *(27') são aceitáveis:

*(27) Ele é enérgico, pode-se até mesmo dizer que ele está com uma cara.

*(27') Ele está com uma cara, pode-se até mesmo dizer que ele é enérgico.

Todas essas observações me levam a dizer que, na ironia não standard do tipo (2), há uma "distanciamento em relação à intensidade" entre o aspecto e o encadeamento: o encadeamento é forte demais em relação ao aspecto que ele concretiza.
Por outro lado, do ponto de vista agora da função textual, o conteúdo da ironia não standard pode ser assumido. Porque o locutor de (2) prossegue assim:

(28) Depois ele se serve disso para remobilizar seu campo: "Quando eu [Hollande] o [Sarkozy] vejo se proteger, eu me digo: "Vamos lutar. Nada é definitivo". (Le Figaro, 7 de abril de 2012).

Vê-se aqui que o locutor desenvolve no discurso o conteúdo do enunciado que precede. Contrariamente ao conteúdo da ironia standard, que é excluído, o conteúdo de (2) é assumido. Resumamos. No caso da ironia não standard baseada no exagero, há um distanciamento em relação à intensidade entre o aspecto argumentativo e o encadeamento argumentativo, e o conteúdo da ironia não standard pode ser assumido.

\subsection{Objeções e respostas}

Poder-se-ia objetar-me que não é o aspecto (24) que o enunciado (2) concretiza em (25), mas antes algo como (29) ou (30):

\section{(29) GANHAR DC CONFIANÇA \\ (30) SUCESSO DC CONFIANÇA}

Para responder a isso, eu presto atenção ao emprego de porque que está em (2). De fato, o segmento porque $x$ dá a instrução de procurar o aspecto na proposição que ele introduz. Em seguida, no caso de (2), o aspecto deve vir da proposição pela leitura de algumas pesquisas, ele seria derrotado menos claramente do que o previsto. Ora, os aspectos (29) e (30) provêm da outra proposição às vezes ele readquire confiança, aquela que não é introduzida por porque. Resulta disso que não é o aspecto (29) ou o (30) que é apropriado à descrição do conteúdo de (2). Aquele que se opõe pensará então em propor o aspecto (31) ou o (32) que seria mais próximo do enunciado (2), e em dizer que não haveria distanciamento no conteúdo do enunciado (2):

\section{(31) NEG DERROTA DC CONFIANÇA (32) NEG DERROTA DC ALEGRIA}

Para responder à segunda objeção, eu presto atenção à presença de um operador negativo menos, na proposição introduzida por porque. De fato, o segmento porque neg $x$ - é o caso de (2), no qual se encontra um operador negativo menos -, dá a instrução de procurar um aspecto normativo cujo segundo segmento contenha NEG, isto é, o aspecto do tipo X DC NEG Y ou NEG X DC 
NEG $\mathrm{Y}^{9}$. Isso se deve ao fato de que o operador de negação no segmento porque neg $x$ instala a negatividade de modo que o aspecto é da forma X DC NEG Y ou NEG X DC NEG Y. Desse ponto de vista, os aspectos (31) e (32), que não contêm o elemento DC NEG Y mas DC Y, também não são apropriados como descrição do conteúdo de (2).

\subsection{Outro exemplo}

Enfim, eu apresentarei outro exemplo de ironia não standard baseada na intensidade, para constatar novamente a presença de um distanciamento sobre a intensidade no conteúdo desse tipo de ironia:

(33) A suspeita de uma aliança entre dirigentes conservadores europeus contra François Hollande continua presente. Tanto mais que ele próprio a alimenta com meias-palavras. "Eu entendo a prudência. Eu vejo as amizades e mais particularmente seu dever de solidariedade. Aquele que se exerce em relação ao presidente que está saindo [Sarkozy] me comove muito particularmente", ironiza ele, esquecendo por um momento que ele acabava de explicar, alguns minutos antes, que ele não falaria de política interna no exterior. (Le Figaro, 10 de março de 2012).

Trata-se de um enunciado de Hollande, durante a campanha da eleição presidencial de 2012, depois de ter encontrado o presidente polonês, mas não o primeiro ministro, cujos poderes são mais amplos (sublinhado pela autora). Eu lembro que, conforme foi visto de início, Hollande é um político de esquerda, e Sarkozy, um homem de direita.

Vê-se que, na ironia não standard (33), o locutor exagera o grau da avaliação antes positiva a respeito do dever de solidariedade exercido em relação a Sarkozy. Assinalo, além disso, que (33) contém um jogo de palavras - a palavra touché pode ser entendida, ou como estar emocionado, quanto como ser visado - mas minha análise será dedicada unicamente à leitura de touché como estar emocionado, que diz respeito à ironia que se baseia na intensidade. Consequentemente, o enunciado aquele que se exerce em relação ao presidente que está saindo me emociona muito particularmente será parafraseado por (35), entendido como concretizando (34):

\footnotetext{
9 Eis, por exemplo, para mostrar que menos do que o previsto é um operador negativo que age sobre derrotado. Em Esperando Godot de Beckett (na página 36 do exemplar publicado pela Édition de Minuit), um personagem que se chama Pozzo diz a respeito do fato de fumar cachimbo: "O segundo é sempre menos bom (ele tira o cachimbo da boca, contempla-o) do que o primeiro, quero dizer (Ele repõe o cachimbo na boca) Mas ele é bom mesmo assim." O mas de mas ele é bom prova que o que precede é argumentativamente contrário a bom: ele é menos bom é um modo de dizer ele é um pouco bom, ele não é verdadeiramente bom. (Carel: comunicação pessoal)
}

(34)

\section{CUMPRE UM DEVER DC NEG Y CRITICA}

Um dever de solidariedade deve ser cumprido em relação ao presidente que está de saída, portanto eu estou emocionado particularmente.

Do mesmo modo que no caso do conteúdo do enunciado (2), observa-se um distanciamento em relação à intensidade entre o segundo segmento do aspecto NEG Y CRITICA e o segundo segmento do encadeamento emocionado muito particularmente. Certamente, cumprir um dever de solidariedade é algo apreciado, mas isso não quer dizer que cumprir um dever de solidariedade seja apreciado a ponto de emocionar alguém muito particularmente. Essa diferença de grau constitui um distanciamento em relação à intensidade. Pode-se fazer o teste com a inserção de até mesmo, como se fez com (2):

(36) Ele não critica isso, pode-se até mesmo dizer que ele está emocionado muito particularmente por isso.

*(36’) Ele está emocionado muito particularmente por isso, pode-se até mesmo dizer que ele não critica isso.

A aceitabilidade do enunciado (36) e a impossibilidade de $*(36 ')$ mostram que há gradualidade entre o segundo segmento do aspecto (34), NEG Y CRITICA e o segundo segmento do encadeamento (35), emocionado muito particularmente.

Quanto à função textual, o conteúdo é evocado desta vez. Pode-se constatar isso na sequência do discurso.

(37) "O que inquieta os conservadores, segundo François Hollande, é a vontade declarada de renegociar o tratado europeu, não para anulá-lo, mas para acrescentar-lhe um item sobre o crescimento e o emprego. Se ele fosse eleito no próximo dia 6 de maio, o candidato socialista se encontraria amplamente isolado na cena europeia, carregando sozinho essa proposta? Mas não o único a reivindicá-la. "Se o povo francês, com seu voto, me der mandato, eu encontrarei mais aliados do que alguns imaginam para reorientar a construção europeia" garante Hollande que se vangloria de ter, com seus deslocamentos, carregado a adesão dos "progressistas" europeus. É, aliás, o caso na Polônia com Leszek Miller que descreve o tratado europeu atual, aquele negociado por Nicolas Sarkozy e Angela Markel, como "um pássaro que só tem uma asa está vivo, mas não pode voar." (Le Figaro, 10 de março de 2012).

Vê-se que o locutor não articula os conteúdos (34) e (35) na sequência do discurso, mas os conteúdos (34) e (35) não fazem aparecer contradição. $O$ conteúdo da ironia não standard pode ser afirmado como vimos com (2), mas também ser evocado como acabamos de observar. 


\section{Balanço e algumas observações}

Resumamos agora o que foi sustentado. Graças à ferramenta fornecida pela TBS, pudemos mostrar ao mesmo tempo a afinidade e a diferença argumentativa que existem entre ironia standard e ironia não standard. Nos dois casos, a presença de distanciamento entre o aspecto e o encadeamento foi constatada. Entretanto, no caso da ironia standard, é um distanciamento absurdo que existe entre o aspecto e o encadeamento, enquanto que é um distanciamento de intensidade que existe entre o aspecto e o encadeamento no caso da ironia não standard. Além disso, a função textual da ironia não standard pode variar - às vezes trata-se de um conteúdo assumido, outras vezes, evocado -, enquanto no caso da ironia standard, o conteúdo é sempre excluído. Se a ironia standard parece mais irônica e a ironia não standard, menos irônica, é que, no caso da ironia standard, o distanciamento é mais saliente porque há contradição, enquanto, no caso da ironia não standard, o distanciamento é menos saliente porque não há contradição, mas somente um distanciamento com relação à intensidade. Dito isso, ambos têm efeito irônico, graças a esse distanciamento de conteúdo.

Além disso, a análise da ironia não standard permite fazer duas observações teóricas. A primeira observação diz respeito à problemática enunciativa. Embora até aqui tenhamos suposto que o conteúdo da ironia é sempre excluído, o conteúdo da ironia não standard não o é sempre. Isso questiona a hipótese de que a função textual de exclusão é um traço comum a todos os enunciados irônicos. Pode-se ir até mesmo mais longe. Até aqui a abordagem assumida para analisar a ironia era quase exclusivamente enunciativa. A ironia é caracterizada principalmente pela "distância enunciativa" - ver, por exemplo, Sperber e Wilson $(1978,1989)$ e Ducrot $(1984,2010)$. Entretanto, como observamos, o conteúdo comunicado pela ironia pode ser, não apenas excluído, mas também assumido e evocado. Certamente, poder-se-ia tentar ignorar os exemplos não standards e manter que a ironia é um fenômeno enunciativo. Pensamos, quanto a nós, que isso é impedir-se de reconhecer uma intuição amplamente compartilhada entre os utilizadores da linguagem, segundo a qual certos enunciados que não são a ironia standard parecem irônicos. Há um parentesco a ser encontrado entre a ironia standard e a ironia não standard e esse parentesco, para nós, não é enunciativo. É argumentativo. Eu me proporei, portanto, a substituir a noção de "distância enunciativa" pela noção de "conteúdo estranhamente distanciado" para explicar a ironia.

A segunda observação diz respeito ao operador NEG. Até aqui, ele é empregado livremente, isto é, sem ter regras explícitas que imponham o emprego desse operador. Entretanto, como se viu, por meio da análise do enunciado (2), certas conjunções poderiam dar, como porque, a instrução de empregar o operador NEG no aspecto argumentativo. Há necessidade de estudos que se interessem por essa questão.

\section{Conclusão}

O objetivo deste artigo foi uma extensão da análise da ironia no quadro da TBS, com vistas a encontrar e descrever linguisticamente um parentesco entre as diversas variedades de ironia. Eu pude tratar, além da ironia standard que já foi objeto de análise, um caso da ironia não standard. Entretanto, há outros tipos de ironia não standard que necessitarão de uma descrição argumentativa. A ironia baseada na comparação é um exemplo (o sublinhado é da autora):

(38) "François Hollande o (Sarkozy) tinha comparado a uma criança desorganizada manipulando uma ardósia mágica” (Le Figaro, 4 de abril de 2012)

Assim, em (38), Hollande resumiu ironicamente cinco anos de mandato de Sarkozy, comparando-o a uma criança para dizer que Sarkozy era infantil como presidente da República: resta saber qual é a natureza desse tipo de enunciado irônico.

\section{Referências}

ANSCOMBRE, Jean-Claude; DUCROT, Oswald. L'argumentation dans la langue. Bruxelles: Mardaga, 1983.

CAREL, Marion. L'entrelacement argumentatif. Paris: Honoré Champion, 2011a.

CAREL, Marion. Ironie, paradoxe et humour. In: GARCÍA, Maria-Dolores Vívero (Éd.). Humour et crises sociales. Paris: L'Harmattan, 2011b. p. 57-74.

CAREL, Marion. Introduction. Argumentation et polyphonie: de Saint-Augustin à Robbe-Grillet. Paris: L'Harmattan, 2012.p. 7-58.

DUCROT, Oswald. Le dire et le dit. Paris: Minuit, 1984.

DUCROT, Oswald. Ironie et négation. In: ATAYAN, Vahram; Wienen, Ursula (Éds.). Ironie et un peu plus: hommage à Oswald Ducrot pour son 80ème anniversaire. Frankfurt: Peter Lang, 2010. p. 169-181.

KERBRAT-ORECCHIONI, Catherine. L'ironie: problèmes de frontière et étude de cas - Sarkozy face à Royal (2 maio 2007). In: GARCÍA, Maria-Dolores Vívero (Éd.). Frontières de l'humour. Paris: L'Harmattan, 2013. p. 27-62.

KIDA, Kohei. Double fonction textuelle de certains contenus. (no prelo a)

KIDA, Kohei. Des paradoxaux aux schémas argumentatifs. (no prelo b).

SPERBER, Don; WILSON, Deirdre. Les ironies comme mentions. Poétique, Paris, n. 36, p. 399-412, 1978.

SPERBER, Don; WILSON, Deirdre. La pertinence. Paris: Minuit, 1989.

Recebido: 30 de novembro de 2014

Aprovado: 18 de fevereiro de 2015

Contato: saori.nishiwak@me.com 